\title{
Rapid closure technique in suboccipital decompression
}

\author{
Martin Vychopen ${ }^{1}\left[\right.$ - Alexis Hadjiathanasiou ${ }^{1}$. Simon Brandecker ${ }^{1} \cdot$ Valeri Borger $^{1} \cdot$ Patrick Schuss $^{1}$. \\ Hartmut Vatter ${ }^{1} \cdot$ Erdem Güresir $^{1}$
}

Received: 30 May 2021 / Accepted: 26 August 2021 / Published online: 25 September 2021

(c) The Author(s) 2021

\begin{abstract}
Objective Suboccipital decompression has been established as standard therapeutic procedure for raised intracranial pressure caused by mass-effect associated pathologies in posterior fossa. Several different surgical techniques of dural closure have been postulated to achieve safe decompression. The aim of this study was to examine the differences between fibrin sealant patch (FSP) and dural reconstruction (DR) in suboccipital decompression for acute mass-effect lesions.

Methods We retrospectively analyzed our institutional data of patients who underwent suboccipital decompression due to spontaneous intracerebellar hemorrhage, cerebellar infarction and acute traumatic subdural hematoma between 2010 and 2019. Two different dural reconstruction techniques were performed according to the attending neurosurgeon: (1) fibrin sealant patch (FSP), and (2) dural reconstruction (DR) including the use of dural patch. Complications, operative time, functional outcome and the necessity of a ventriculoperitoneal shunt (VP Shunt) were assessed and further analyzed.

Results Overall, 87 patients were treated at the authors' institution (44 in FSP group, 43 in DR group). Glasgow coma scale on admission and preoperative coagulation state did not differ between the groups. Postoperatively, we found no difference in cerebrospinal fluid leakage or chronic hydrocephalus between the groups $(p=0.47)$. Revision rates were $2.27 \%(1 / 44$ patients) in the FSP group, compared to $16.27 \%(7 / 43)$ in the DR group $(p<0.023)$. Operative time was significantly shorter in the FSP group $(90.3 \pm 31.0$ min vs. $199.0 \pm 48.8 \mathrm{~min}, p<0.0001)$.

Conclusion Rapid closure technique in suboccipital decompression is feasible and safe. Operative time is hereby reduced, without increasing complication rates.
\end{abstract}

Keywords Suboccipital $\cdot$ Decompression $\cdot$ Rapid closure

\section{Introduction}

Martin Vychopen

martin.vychopen@ukbonn.com

Alexis Hadjiathanasiou

alexis.hadjiathanasiou@ukbonn.de

Simon Brandecker

simon.brandecker@ukbonn.de

Valeri Borger

valeri.borger@ukbonn.de

Patrick Schuss

patrick.schuss@ukbonn.de

Hartmut Vatter

hartmut.vatter@ukbonn.de

Erdem Güresir

erdem.gueresir@ukbonn.de

1 Department of Neurosurgery, University Hospital Bonn, Venusberg-Campus 1, 53127 Bonn, Germany
Suboccipital decompressive craniectomy (SDC) is widely used for patients suffering from raised intracranial pressure caused by cerebellar infarction $[1,2]$. In a retrospective analysis of patients suffering from spontaneous cerebellar hemorrhage, SDC proved to be the most beneficial, compared to craniotomy and evacuation of haematoma, external ventricular drainage alone, or conservative treatment [3]. Similar results have also been published for patients with cerebellar infarction [13].

Various surgical techniques for watertight dural reconstruction were introduced in the literature [4-7]. However, the use of dural grafts is a time consuming procedure, which might cause additional complications [8]. For supratentorial craniectomy, a randomized trial showed rapid-closure technique to be safe procedure reducing operative time and costs of the operation without significantly higher incidence 
of surgical complications [9]. The necessity of dural graft in SDC is still underinvestigated. The aim of our study was to analyze and compare the use of fibrin sealant patch with surgical reconstruction using dural grafts.

\section{Methods}

We performed a single-center retrospective study of consecutive patients undergoing SDC for cerebellar hemorrhage, cerebellar infarction, and cerebellar subdural hematomas, treated between 01/2008 and 01/2020. Patients underwent computed tomography scan (CT) at admission, as well as CT-angiography scan (CT-A). We excluded patients with subarachnoid hemorrhage and hemorrhage from other vascular malformations, as well as benign or malignant oncological pathologies in the posterior fossa. Two surgical methods were performed depending on the officiating neurosurgeon: (1) fibrin sealant patch (FSP group), where fibrin sealant was used to cover the dural defect, without watertight suture or extension duraplasty, and (2) dural reconstruction group (DR) with artificial dural substitute or Musclepatch (Fig. 1). All patients received an external ventricular drain to prevent acute obstructive hydrocephalus. Clinical, radiological, and laboratory parameters (Quick, INR, aPTT, hemoglobin, and hematocrit) were included for further analysis. Furthermore, operative time, blood loss, and surgical technique as well as postoperative complications were analyzed. Finally, we performed the comparative analysis according to the underlying
1

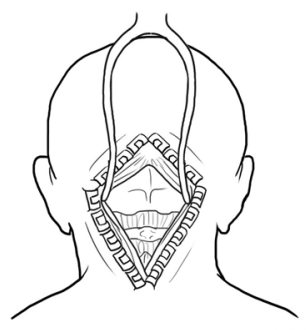

$3 a$

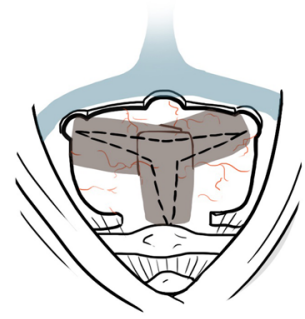

2

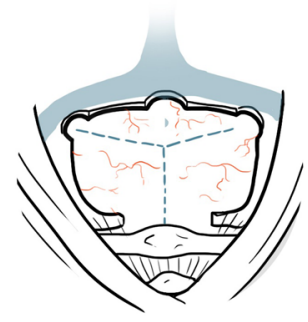

$3 b$

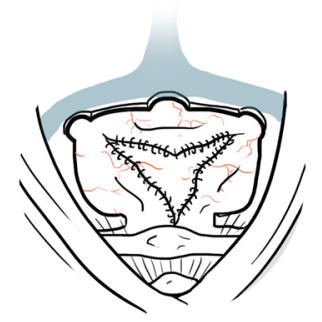

Fig. 1 Suboccipital decompression. 1. Skin and muscle incision. 2. Bony decompression. 3a. Fibrin sealant patch closure (FSP group). 3 b. Surgical reconstruction group with extension dural plastic (DR group) pathologies. The size of the mass lesions was measured in preoperative $\mathrm{CT}$ scan using $\mathrm{ABC} / 2$ method [18].

\section{Surgical technique}

All decompressions were performed in standardized fashion. Patients were treated by external ventricular drainage (EVD) for hydrocephalus and SDC subsequently. The patient is placed in a prone position and the head is placed in the 3-pin Mayfield skullclamp maximum inclined. A 3-cm-wide strip is shaved along the planned incision. The skin and muscles are dissected and lifted of the bone (Fig. 1.1).

Bilateral SDC with extension to foramen magnum was performed in all patients. The margins of the SDC are placed as close as possible to sinus transversus and lateral sinuses [13]. The dura is opened widely in a stellate fashion (Fig. 1.2).

In the FSP group, the remaining dura is used to cover the brain tissue and Fibrin sealant patch is used just to cover the dural defect. No surgical duraplasty is performed, no patch or dural substitute is used (Fig. 1.3a).

In the DR group, an extension duraplasty is performed (Fig. 1.3b).

After the suboccipital craniectomy, the patients were evaluated for the necessity of permanent cerebrospinal fluid (CSF) drainage and received either a VP Shunt or the EVD was removed. Factors associated with the development of hydrocephalus, such as the length of the periprocedural external ventricular drain placement and chronic hydrocephalus development were examined. Functional neurological outcome was assessed with the modified Rankin scale (mRS) and stratified in favorable ( $\mathrm{mRS} \mathrm{0-2)}$ vs. unfavorable (mRS 3-6).

\section{Statistics}

Statistical analysis was performed using an unpaired $t$-test for parametric variables. Categorical variables were analyzed in contingency tables using the Fisher's exact test. Results with $p<0.05$ were considered significant. Data analyses were performed using the computer software package SPSS (version 25, IBM Corp., Armonk, NY). Mann-Whitney $U$ test was used to compare the GCS by admission.

\section{Results}

Between 01/2008 and 01/2020, SDC was performed in 338 patients. 251 patients were excluded due to: subarachnoid hemorrhage $(n=6)$, hemangioma $(n=29)$, tumor/metastasis $(n=154)$, Arnold-Chiari malformation $(n=38)$ and arteriovenous malformation $(n=24)$. Overall, 87 patients were included in the analysis (Table 1). 
Table 1 Patient characteristics

\begin{tabular}{ll}
\hline Sex & \\
\hline Male & $50(57.4 \%)$ \\
Female & $37(42.6 \%)$ \\
Underlying pathology & \\
Cerebellar infarction & $29(33.3 \%)$ \\
Cerebellar hemorrhage & $56(64.4 \%)$ \\
Suboccipital subdural hematoma & $2(2.3 \%)$ \\
Mean age ( \pm SD) in years & $66.3 \pm 13.9$ \\
Number of Patients & 87 \\
FSP group & $44(50.5 \%)$ \\
SR group & $43(49.5 \%)$
\end{tabular}

$S D$ standard deviation, FSP group fibrin sealant patch group, $S R$ group surgical reconstruction group

Table 2 Preoperative coagulation state

\begin{tabular}{llll}
\hline & FSP group $(n=44)$ & DR group $(n=43)$ & \\
\hline Platelet count & $187 \pm 67.4 \mathrm{G} / \mathrm{l}$ & $196 \pm 76.2 \mathrm{G} / 1$ & $p=0.56$ \\
Quick & $83,3 \pm 22.1 \%$ & $83.3 \pm 26.5 \%$ & $p=1.00$ \\
INR & 1.2 & 1.2 & \\
aPTT & $24.6 \mathrm{~s}$ & $25.7 \mathrm{~s}$ & \\
Hemoglobin & $12.3 \pm 1.9 \mathrm{~g} / \mathrm{dl}$ & $12.7 \pm 2.4 \mathrm{~g} / \mathrm{dl}$ & $p=0.39$ \\
\hline
\end{tabular}

FSP group fibrin sealant patch group, DR group dural reconstruction group, INR international normalized ratio, $a P T T$ activated partial thromboplastin time

\section{Preoperative status}

No significant differences in Quick, International normalized ratio (INR), activated partial thromboplastin time (aPTT), hemoglobin, platelet count, or platelet function testing (PFA) were found between the two groups. For detailed information, see Table 2.

The median values of GCS between the groups were 6.0 in FSP group vs 7.5 in DR group, did not show any significant difference $(p=0.92)$.

\section{Intraoperative findings}

Patients in the FSP group had significantly lower blood loss compared to patients in the DR group $(341.4 \pm 313.0 \mathrm{ml}$ vs. $839.5 \pm 508.2 \mathrm{ml} ; p<0.0001)$.

Operative time was significantly shorter in the FSP group compared to the DR group $(90.3 \pm 31.0 \mathrm{~min}$. vs. $199.0 \pm 48.8 \mathrm{~min} ; p<0.0001)$. This statement is strongly limited by different factors: In four patients, second operation was necessary to acquire fascia lata, which was used as dural graft. Furthermore, the microscope was deemed necessary to perform the dural reconstruction, whereas in
FSP group, dural closure was performed macroscopically. Finally, we found time-variations depending on the attending neurosurgical team.

\section{Postoperative complications}

Overall, eight patients suffered from complications needing surgical revision. One patient in the FSP group underwent surgical revision for abscess formation and seven patients in the DR group underwent surgical revision (one patient for abscess, six patients for re-bleeding); $p=0.02$.

\section{Hydrocephalus}

There was no difference in the number of patients who developed hydrocephalus in both groups (6 in FSP group vs. 7 in DR group; $p=0.7$ ). In the FSP group, five patients received VP-Shunt, whereas in the DR group, three patients received VP-Shunt. However, two patients in the FSP group and four patients in the DR group deceased because of nonneurosurgical complications before receiving a VP-Shunt. The mean length of external ventricular drainage placement was $8.7 \pm 7.6$ days for the FSP group vs. $8.4 \pm 8.9$ days for the DR group; $p=0.8$.

\section{Outcome}

16 patients in the FSP group vs. 13 patients in the DR group achieved favorable outcome at 6 months $(p=0.4)$.

\section{Underlying pathologies}

We found no significant difference in distribution of underlying pathologies or size of the lesion among the groups.

We confirmed the significant difference in blood loss and operative time between the groups. For detailed information, see Table 2.

\section{Discussion}

In patients undergoing SDC for cerebellar infarction or hemorrhage, various techniques exist to avoid CSF leakage, since this is one of the most common complications. On the other side, mass-effect lesions in the posterior fossa lead to direct compression of the brainsteam [15]. Patients suffering from such pathologies need rapid treatment [13] (Table 3). Decompression of the posterior fossa is established as an effective treatment. In many retrospective studies, various techniques are described from suboccipital craniotomy with removal of the hemorrhage or infarction, craniectomy without removal of the hemorrhage or infarction, or suboccipital craniectomy with removal of the hemorrhage or 
Table 3 Underlying pathologies

\begin{tabular}{|c|c|c|c|}
\hline & FSP ICH & DR ICH & \\
\hline$n$ & 29 & 28 & \\
\hline Lesion size $\left(\mathrm{cm}^{3}\right)$ & $25.26 \pm 15.6$ & $26.92 \pm 10.3$ & $p=0.63$ \\
\hline OP-time (min) & $91.17 \pm 65.05$ & $199.03 \pm 68.23$ & $p<0.0001$ \\
\hline \multirow[t]{2}{*}{ Blood loss (ml) } & $362.0 \pm 460.73$ & $830.35 \pm 532.60$ & $p=0.0008$ \\
\hline & FSP CI & DR CI & \\
\hline$n$ & 14 & 15 & \\
\hline Lesion size $\left(\mathrm{cm}^{3}\right)$ & $39.26 \pm 14.5$ & $36.14 \pm 10.3$ & $p=0.50$ \\
\hline OP-time (min) & $89.64 \pm 24.77$ & $199.46 \pm 58.46$ & $p<0.0001$ \\
\hline Blood loss (ml) & $346.42 \pm 406.27$ & $815.62 \pm 524.92$ & $p=0.012$ \\
\hline
\end{tabular}

FSP ICH fibrin sealant patch group with intracerebellar hemorrhage, FSP CI fibrin sealant patch group with cerebellar infarction, $D R I C H$ dural reconstruction group with intracerebellar hemorrhage, $D R C I$ dural reconstruction group with cerebellar infarction, $O P$-time operative time, $N$ number of patients

infarction [14]. Data regarding suboccipital decompression without watertight surgical reconstruction of dura mater is scarce. Previously, decompression without watertight surgical reconstruction of dura mater has already been introduced in supratentorial decompression $[9,10]$. In the present study two techniques for dural reconstruction were performed according to the decision of the attending neurosurgeon, allowing a clear stratification of the patients.

\section{Surgical complications}

Patients in the DR group showed significantly higher rates of surgical revisions. There was no difference in infectious complications and wound healing disturbances. However, the bleeding complications were significantly more common among the patients in DR group $(p=0.01)$. Although the surgical technique had no influence on neurological outcome at 6 months in general, the neurological outcome of all patients with bleeding complications was unfavorable $(90 \%$ deceased). A pathological preoperative coagulation state in any of the groups was ruled out.

\section{Hydrocephalus}

The development of chronic hydrocephalus and the necessity for VP-Shunt placement did not differ between the groups. Mangubat et al. described a rate of CSF disturbances in patients with pathology in the posterior fossa at $15 \%$ and slightly higher incidence for ICH compared to cerebellar infarction (5/42, 11\% ICH vs. 1/14, 7\%) [11]. In our study, similar results were found $(14 \%)$. We observed higher rates of permanent hydrocephalus in patients with cerebellar hemorrhage in comparison to cerebellar ischemia (9 vs. 4). In eight of nine patients with cerebellar hemorrhage, coexistent intraventricular hemorrhage was noted, which is a known predictor for hydrocephalus development $[12,14]$.

\section{Operative time}

We confirmed the hypothesis of reducing time by using Fibrin sealant patch in suboccipital dura closure. The same has already been proven for supratentoriell decompressive craniectomy $[9,10]$. Although being biased by several factors, the hypothesis of reducing time by using fibrin sealant patch in suboccipital dura closure was confirmed in our cohort. In general, shortening the duration of surgical procedures enhances their safety [16], especially when treating critically ill patients, and might reduce blood loss and rates of infection. It saves resources-in addition to the costs of the artificial implant—which is under the current health care policy of economic interest, as pointed out by Horaczek et al. [17]. As a result of the present retrospective institutional analysis, we changed our institutional treatment policy completely to dural closure via fibrin sealant patch alone due to shorter operation time, lower blood loss, reduced rebleeding needing surgical revision, without influencing the rate of CSF leakage.

\section{Limitations}

The present study has several limitations. Acquisition of data was retrospective and represents only a single-center experience. Furthermore, the type of dural closure technique was performed only according to the attending neurosurgeon. The use of external ventricular drain might limit the assessment of both dural reconstruction techniques. However, this might be partially outweighed by the fact that all patients received EVD before suboccipital decompression and was used for CSF drainage on a standardized protocol. The analysis of the operative time was strongly biased by different techniques of acquiring the patch (fascia lata vs. synthetical 
material) and the art of dural closure (microscopically in DR vs. macroscopically in FSP).

\section{Conclusion}

Suboccipital decompressive craniectomy with Fibrin sealant patch dural closure is a safe procedure. Through this technique surgical time, blood loss, and complications needing surgical revision are reduced.

Author contribution MV: study design, data collection and interpretation, manuscript writing. AH, SB, VB, PS, HV: critical revision. EG: study design, data interpretation, proofreading, literature search.

Funding Open Access funding enabled and organized by Projekt DEAL. There are no financial conflicts of interest to disclose.

Availability of data and material Data available on request due to privacy/ethical restrictions.

Code availability Not applicable.

\section{Declarations}

Conflict of interest The authors whose names are listed below certify that they have NO affiliations with or involvement in any organization or entity with any financial or non-financial interest (such as personal or professional relationships, affiliations, knowledge or beliefs) in the subject matter or materials discussed in this manuscript.

Ethics approval Ethik Komission der Rheinische Friedrich-Wilhelms Universität Nr.427/20.

Consent to participate Not applicable.

Consent for publication Not applicable.

Open Access This article is licensed under a Creative Commons Attribution 4.0 International License, which permits use, sharing, adaptation, distribution and reproduction in any medium or format, as long as you give appropriate credit to the original author(s) and the source, provide a link to the Creative Commons licence, and indicate if changes were made. The images or other third party material in this article are included in the article's Creative Commons licence, unless indicated otherwise in a credit line to the material. If material is not included in the article's Creative Commons licence and your intended use is not permitted by statutory regulation or exceeds the permitted use, you will need to obtain permission directly from the copyright holder. To view a copy of this licence, visit http://creativecommons.org/licenses/by/4.0/.

\section{References}

1. Lindeskog D, Lilja-Cyron A, Kelsen J, Juhler M. Long-term functional outcome after decompressive suboccipital craniectomy for space-occupying cerebellar infarction. Clin Neurol Neurosurg.
2019;176:47-52. https://doi.org/10.1016/j.clineuro.2018.11.023 (Epub 2018 Dec 1 PMID: 30522035).

2. Hackenberg KA, Unterberg AW, Jung CS, Bösel J, Schönenberger $\mathrm{S}$, Zweckberger K. Does suboccipital decompression and evacuation of intraparenchymal hematoma improve neurological outcome in patients with spontaneous cerebellar hemorrhage? Clin Neurol Neurosurg. 2017;155:22-9. https://doi.org/10.1016/j.cline uro.2017.01.019 (Epub 2017 Feb 3 PMID: 28226284).

3. Kirollos RW, Tyagi AK, Ross SA, van Hille PT, Marks PV. Management of spontaneous cerebellar hematomas: a prospective treatment protocol. Neurosurgery. 2001;49(6):1378-86. https:// doi.org/10.1097/00006123-200112000-00015 (discussion 1386-7 PMID: 11846937)

4. Berjano R, Vinas FC, Dujovny M. A review of dural substitutes used in neurosurgery. Crit Rev Neurosurg. 1999;9(4):217-22. https://doi.org/10.1007/s003290050136 (PMID: 10436210).

5. Schiariti M, Acerbi F, Broggi M, Tringali G, Raggi A, Broggi G, Ferroli P. Two alternative dural sealing techniques in posterior fossa surgery: (Polylactide-co-glycolide) self-adhesive resorbable membrane versus polyethylene glycol hydrogel. Surg Neurol Int. 2014;3(5):171. https://doi.org/10.4103/2152-7806.146154 (PMI D:25593755;PMCID:PMC4287912).

6. Kawai H, Nakagawa I, Nishimura F, Motoyama Y, Park YS, Nakamura M, Nakase H, Suzuki S, Ikada Y. Usefulness of a new gelatin glue sealant system for dural closure in a rat durotomy model. Neurol Med Chir (Tokyo). 2014;54(8):640-6. https://doi.org/10. 2176/nmc.oa.2014-0005 (Epub 2014 Jul 28. PMID: 25070015; PMCID: PMC4533497).

7. Azzam D, Romiyo P, Nguyen T, Sheppard JP, Alkhalid Y, Lagman C, Prashant GN, Yang I. Dural repair in cranial surgery is associated with moderate rates of complications with both autologous and nonautologous dural substitutes. World Neurosurg. 2018;113:244-8. https://doi.org/10.1016/j.wneu.2018.01.115 (Epub 2018 Jan 31 PMID: 29374609).

8. Güresir E, Vatter H, Schuss P, Oszvald A, Raabe A, Seifert V, Beck J. Rapid closure technique in decompressive craniectomy. J Neurosurg. 2011;114(4):954-60. https://doi.org/10.3171/2009. 12.JNS091065 (Epub 2010 Jan 29 PMID: 20113157).

9. Vieira E, Guimarães TC, Faquini IV, Silva JL, Saboia T, Andrade RVCL, Gemir TL, Neri VC, Almeida NS, Azevedo-Filho HRC. Randomized controlled study comparing 2 surgical techniques for decompressive craniectomy: with watertight duraplasty and without watertight duraplasty. J Neurosurg. 2018;129(4):1017-23. https://doi.org/10.3171/2017.4.JNS152954 (Epub 2017 Nov 17 PMID: 29148904).

10. Mangubat EZ, Chan M, Ruland S, Roitberg BZ. Hydrocephalus in posterior fossa lesions: ventriculostomy and permanent shunt rates by diagnosis. Neurol Res. 2009;31(7):668-73. https://doi. org/10.1179/174313209X380937 (Epub 2008 Dec 23 PMID: 19108752).

11. Bhattathiri PS, Gregson B, Prasad KS, Mendelow AD, STICH Investigators. Intraventricular hemorrhage and hydrocephalus after spontaneous intracerebral hemorrhage: results from the STICH trial. Acta Neurochir Suppl. 2006;96:65-8. https://doi. org/10.1007/3-211-30714-1_16 (PMID: 16671427).

12. Hwang BY, Bruce SS, Appelboom G, Piazza MA, Carpenter AM, Gigante PR, Kellner CP, Ducruet AF, Kellner MA, DebSen R, Vaughan KA, Meyers PM, Connolly ES Jr. Evaluation of intraventricular hemorrhage assessment methods for predicting outcome following intracerebral hemorrhage. J Neurosurg. 2012;116(1):185-92. https://doi.org/10.3171/2011.9.JNS10850 (Epub 2011 Oct 14 PMID: 21999319).

13. Kim MJ, Park SK, Song J, Oh SY, Lim YC, Sim SY, Shin YS, Chung J. Preventive suboccipital decompressive craniectomy for cerebellar infarction: a retrospective-matched case-control study. 
Stroke. 2016;47(10):2565-73. https://doi.org/10.1161/STROK EAHA.116.014078 (Epub 2016 Sep 8 PMID: 27608818).

14. Ayling OGS, Alotaibi NM, Wang JZ, Fatehi M, Ibrahim GM, Benavente O, Field TS, Gooderham PA, Macdonald RL. Suboccipital decompressive craniectomy for cerebellar infarction: a systematic review and meta-analysis. World Neurosurg. 2018;110:450-459.e5. https://doi.org/10.1016/j.wneu.2017.10.144 (Epub 2017 Dec 2 PMID: 29104155).

15. Neugebauer H, Witsch J, Zweckberger K, Jüttler E. Space-occupying cerebellar infarction: complications, treatment, and outcome. Neurosurg Focus. 2013;34(5):E8. https://doi.org/10.3171/2013.2. FOCUS12363 (PMID: 23634927).

16. Korinek AM. Risk factors for neurosurgical site infections after craniotomy: a prospective multicenter study of 2944 patients.
The French Study Group of Neurosurgical Infections, the SEHP, and the C-CLIN Paris-Nord. Service Epidémiologie Hygiène et Prévention. Neurosurgery. 1997;41(5):1073-9. https://doi.org/10. 1097/00006123-199711000-00010 (discussion 1079-81 PMID: 9361061).

17. Horaczek JA, Zierski J, Graewe A. Collagen matrix in decompressive hemicraniectomy. Neurosurgery. 2008;63(1 Suppl 1):ONS176-81. https://doi.org/10.1227/01.neu.0000335033. 08274.1c (discussion ONS181 PMID: 18728597).

18. Kothari RU, Brott T, Broderick JP, Barsan WG, Sauerbeck LR, Zuccarello M, Khoury J. The ABCs of measuring intracerebral hemorrhage volumes. Stroke. 1996;27(8):1304-5. https://doi.org/ 10.1161/01.str.27.8.1304 (PMID: 8711791). 